\title{
ESTUDIO SOBRE UN RELIEVE IDENTIFICADO RECIENTEMENTE COMO HUASTECO
}

\section{Nelly Gutiérrez Solana}

La cultura huasteca nos legó un gran número de esculturas de bulto y una cantidad menor de relieves, los cuales, hasta la fecha, han sido poco estudiados. El pueblo huasteco habitó la región comprendida actualmente por los estados de Tamaulipas, Veracruz, San Luis Potosí, Hidalgo y partes de Querétaro y Puebla. Aunque es difícil determinar con exactitud el desarrollo temporal de dicha cultura, todo parece indicar que su máximo florecimiento artístico abarcó desde el periodo clásico hasta el posclásico temprano

$\mathrm{Al}$ observar las esculturas huastecas llama la atención la desigualdad de su calidad; unas son excepcionales en cuanto a la perfección de su labrado, otras muestran una factura tosca. Entre las piezas sobresalientes tenemos la conocida bajo el nombre del "Adolescente Huasteco" y otra, asombrosa en verdad, conservada en el museo de Brooklyn, la cual representa a un hombre con un esqueleto a cuestas. La calidad estética extraordinaria de estas esculturas permite incluirlas entre las obras más destacadas de la época prehispánica. ¿Cómo explicarse que junto a ellas haya cientos de monolitos los cuales merecen el calificativo de burdos? Una posible explicación es la existencia de talleres en los cuales se formaba a los artífices a través de un largo entrenamiento en el uso de las técnicas adecuadas, y precisamente en estos talleres es donde se realizaban las mejores tallas. La tesis reciente de la maestra Silvia Trejo apunta al desarrollo de un estilo escultórico dentro del área del Río Tamuín. En este artículo me referiré a tres relieves que parecen indicar la existencia de una escuela local en el sitio de Huilocintla, al norte del estado de Veracruz.

El relieve fragmentado, tema principal de este estudio, se incluyó en un catálogo publicado en 1963 con el título de Sculpiure en Pierre de L'Añcien Mexique, en el que se ilustraron piezas de una exposición de esculturas del México prehispánico, llevada a cabo en la Galería Jeanne Bucher de París. En este catálogo se clasificó dicho relieve como maya-tolteca y se da como su lugar de origen al centro ceremonial de Uxmal en Yucatán. Al revisar dicho catálogo me di cuenta que esto era un error, pues su gran similitud con dos lápidas de Huilocintla permite pensar que también procede de dicho sitio. Huilocintla se encuentra cerca de Castillo de Teayo y de otros asentamientos prehispánicos al norte del estado de Veracruz, en los cuales se han hallado muchas esculturas huastecas

El relieve, al cual me refiero en el párrafo anterior, ayuda a fundamentar la creencia de que en Huilocintla existió un taller especializado en relieve, el cual se distinguió por la gran calidad de sus obras y por ciertos rasgos tanto formales como iconográficos. De este taller provienen, hasta el momento, tres piezas principales: la famosa lápida de Huilocintla conservada en el Museo 
Nacional de Antropología; otra lápida que, según nos informa Eduard Seler, también procede del mismo sitio, y la cual se encuentra en el Museo Etnográfico de Berlín; y el fragmento dado a conocer gracias al catálogo francés. La temática de las tres obras es la misma: un personaje se autosacrifica al pasar una vara a través de su lengua. En el fragmento sólo se conserva el rostro de la figura, en cambio en las otras dos lápidas está el personaje completo, erecto y con los pies bastante separados entre sí.

La lápida de nuestro museo representa a un personaje que se perfora la lengua con una vara; frente a él hay un pequeño ser fantástico de cuyas fauces dobles emerge un ganchito con el cual recibe la sangre del penitente. La obra del museo berlinés muestra a la figura principal acompañada, por otras dos: un ser esquelético y un hombre con tocado zoomorfo; este último porta un escudo, un haz de dardos y un estandarte. En ambos relieves se esculpió, junto al personaje principal, la fecha 'uno jaguar', la cual indica probablemente el nombre del mismo, ya que, en el México prehispánico, los nombres de los días servían para designar a las deidades y a los hombres.

El relieve del catálogo francés mide $44 \mathrm{cms}$. de altura y se talló en piedra arenisca que es el tipo de piedra más utilizado en las esculturas huastecas. Del personaje se conserva únicamente el rostro visto de perfil, una mano colocada cerca de la boca y parte de su tocado, además de otros elementos secundarios. Puede mirarse claramente cómo dicho personaje traspasa su lengua saliente con una vara.

Son varias las caracteristicas que permiten establecer un origen común para estas tres obras. Las tres son de una factura extraordinaria lo cual permite representar, con toda precisión, hasta el más mínimo detalle. En la pieza mejor conservada, la del Museo Nacional de Antropología, los contornos principales de la composición se realizaron en un relieve bastante saliente, mientras que los secundarios se lograron con un relieve más bajo o por medio de la incisión. El pequeño jaguar que, junto con el numeral uno, indica el nombre del personaje representado en la lápida, es un ejemplo del uso de un relieve bastante plano. (Dícho jaguar no se álcanza a distinguir en la fotografía)

Otra similitud importante entre estas tres obras es el tipo de rostro estilizado, de nariz grande y casi recta. El ojo se compone de dos círculos concéntricos, con la particularidad de que el exterior tiene una pequeña prolongación. Este tipo de ojo es común dentro del arte huasteco, ya que lo encontramos también en algunas de las figuras del mural de Tamuín, y en otras talladas en objetos de concha de origen huasteco. Sobre las mejillas de los tres personajes se marcaron elementos triangulares, y los tocados parecen estar sostenidos por cuerdas colocadas entre la cara y la oreja

Los tocados elaborados ostentados por las figuras principales de las dos lápidas y del fragmento son singulares pues no aparecen en ninguna de las otras figuras huastecas talladas en piedra o pintadas. La mayoría de los tocados de las piezas huastecas son en forma de abanico o consisten de un bloque trapezoidal sobre el cual se coloca un objeto cónico; en ocasiones adoptan la 


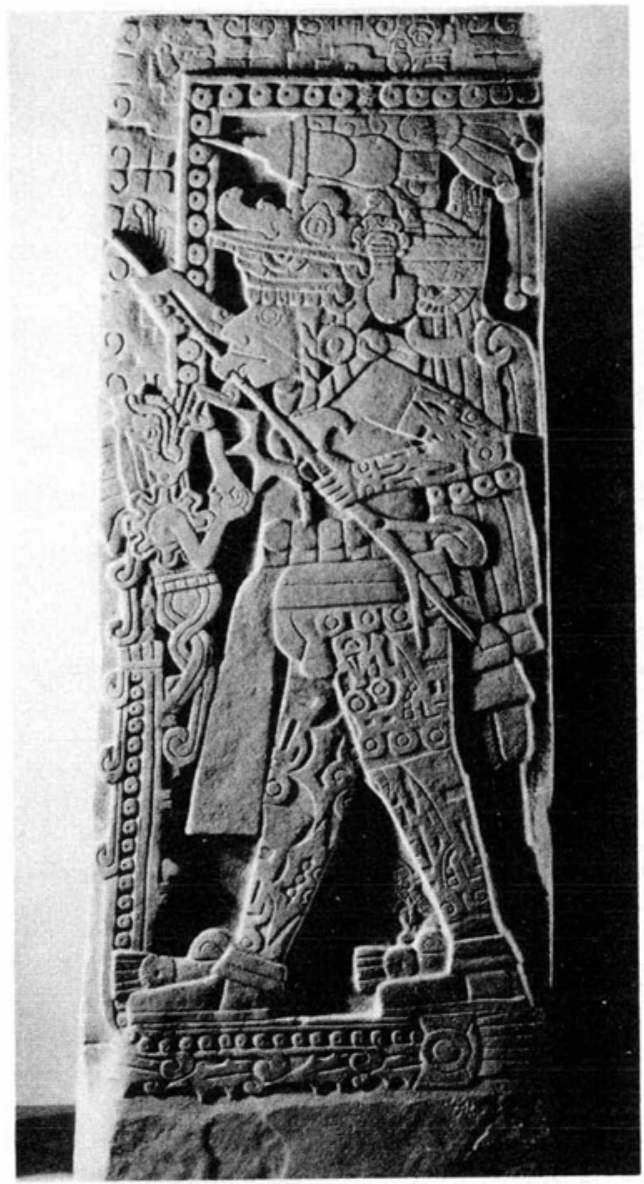

Figura 1. Lápida de Huilocintla del Museo Nacional de Antropología, México.
Figura 2. Lápida de Huilocintla del Museo Etnográfico de Berlín.

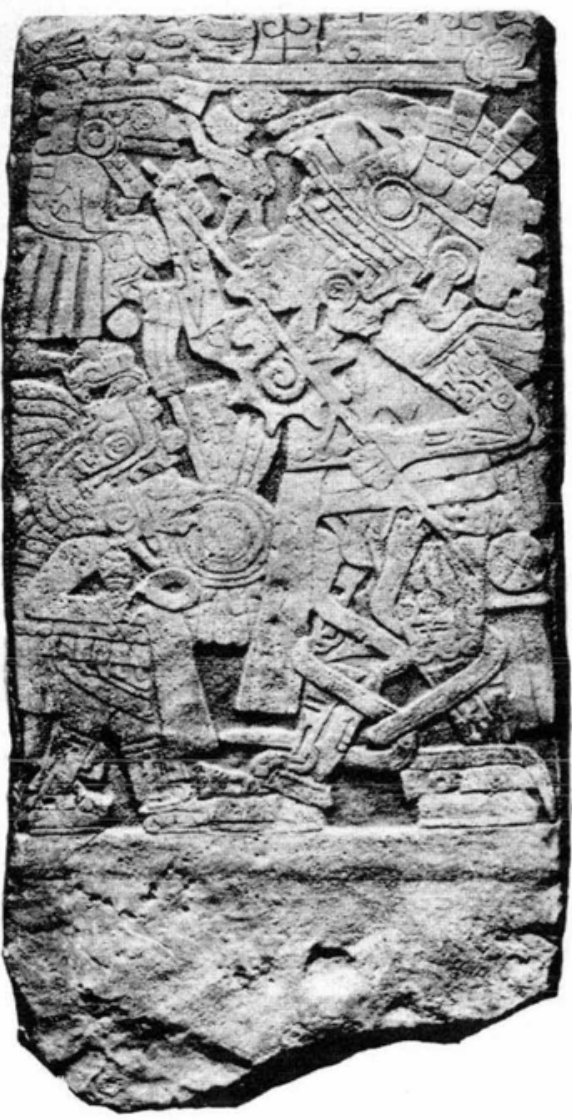


DOI: http://dx.doi.org/10.22201/iie.18703062e.1982.50\%20Tomo\%201.1134

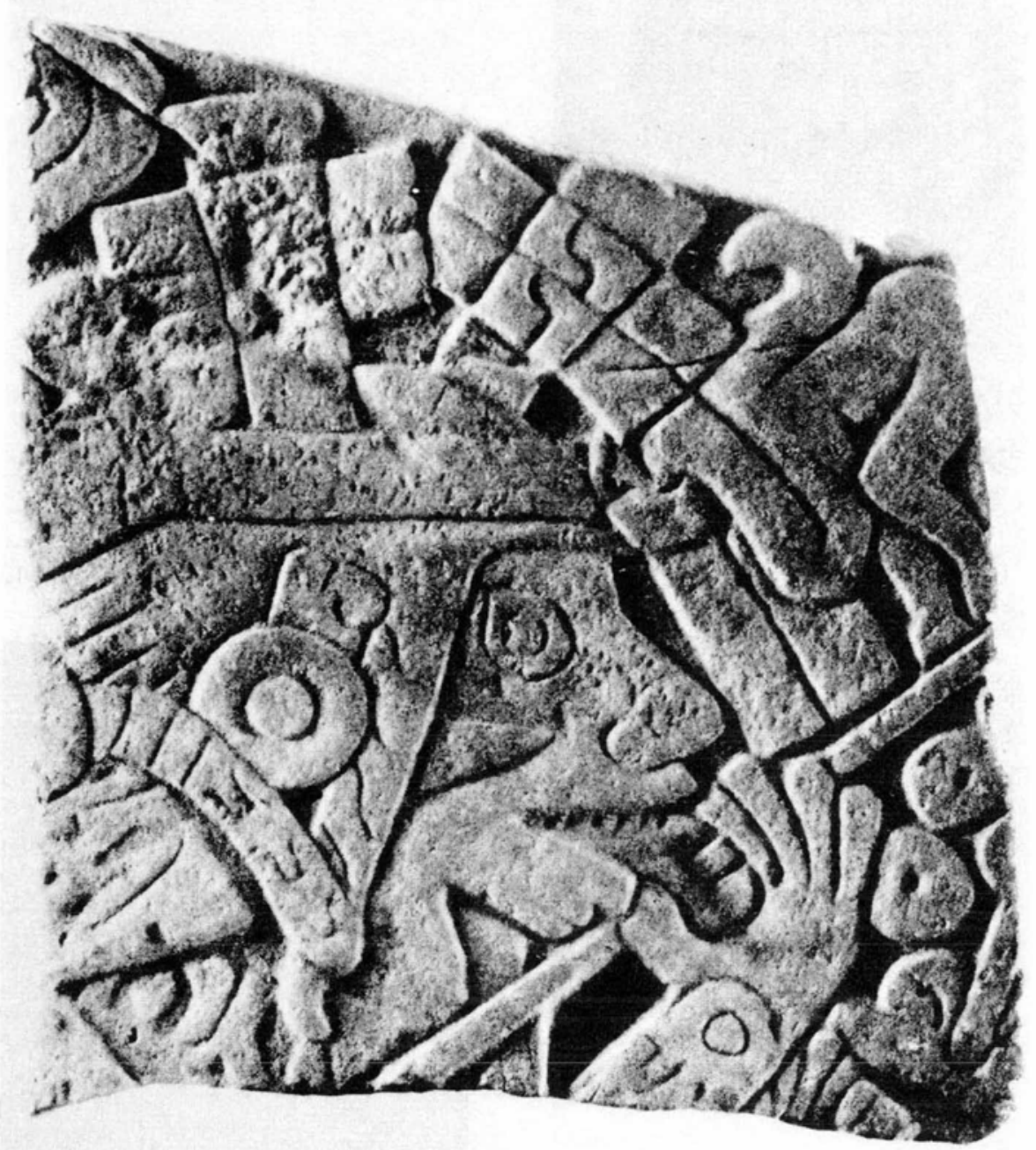

Figura 3. Lápida fragmentada identificada como perteneciente a la cultura huasteca. 
forma de un yelmo que enmarca al rostro de la figura En las lápidas de Huilocintla, los tocados tienen dos máscaras colocadas una sobre la otra, y la superior, que se distingue con mayor claridad, presenta un pico de forma extraña que se curva hacia arriba. Ambos tocados llevan además en la parte superior, un elemento puntiagudo que, en el caso de la obra de Berlín, se corona con dos objetos cruciformes. Dichos objelos, que también forman parte del tocado usado por el personaje del relieve frágmentado, se compone de franjas alargadas con lo que parecen ser dos moños colocados perpendiculares a ellas.

Al observar los relieves de Huilocintla sobresalen dos características formales: el espacio muy reducido que se deja sin labrar y la fragmentación excesiva de las superficies ya que los cuerpos, adornos y demás elementos se dividen en un gran número de detalles. Estos dos rasgos formales son también distintivos de los murales de Tamuín y de los objetos de concha En cambio, es notoria la diferencia entre la proporción de las figuras de los relieves y las pintadas en Tamuin o las talladas en concha. En las primeras, la proporción es de siete cabezas, mientras que algunas de las otras llegan a tener una proporción de tres a cuatro cabezas. La proporción de las figuras de los relieves se acerca más a la de algunas esculturas en bulto, como la conocida como ' $\mathrm{El}$ Adolescente', cuya proporción es de seis cabezas.

Los habitantes de la región huasteca gustaban de cubrir sus cuerpos y sus caras con diseños variados, testimonio de ello son las esculturas y los relieves. En los rostros es común encontrar un triángulo o un reborde estrecho sobre las mejillas. Los cuerpos aparecen adornados con: círculos divididos, ocasionalmente, en cuatro secciones; diseños de corte de caracol, algunos de los cuales tienen en su interior tres círculos pequeños y se limitan con elementos puntiagudos; $y$, también, cabezas de aves vistas de perfil. En el fragmento de relieve, aqui estudiado, se percibe un triángulo sobre la mejilla y un círculo doble cubre la muñeca de la única mano que se conserva.

En este mismo relieve hay un deialle quue merece nuestra atención. El espacio frente al tocado y frente a la parte superior de la cara del personaje lo ocupa una pequeña figura humana inclinada hacia adelante, de tal manera que el tronco queda casi perpendicular a las piernas. El contorno del cuerpo, que carece de cabeza, es más fluido y suave en comparación con las líneas rectas utilizadas para la mayor parte del relieve. El brazo de la figurita se flexiona sobre sí mismo y se prolonga con una banda; otra franja se origina en la espalda y termina en un gancho. Este mismo tipo de imagen aparece en un pendiente de concha del Museo Etnográfico de Berlín. La composición de dicho pendiente es muy complicada, pero puede distinguirse la parte inferior de dos figuras humanas de cuyos torsos emergen fajas anchas que se entrelazan para terminar en cabezas de serpientes.

El personaje que se autosacrifica en las lápidas de Huilocintla ha sido identificado, por algunos estudiosos, como el dios Ehécatl Quetzalcóatl, una de las deidades principales del panteón mesoamericano. Esta identificación se 
basa esencialmente en el pectoral, en forma de caracol, que porta; este tipo de pectoral es uno de los atributos más distintivos de este numen. Para otros investigadores no es propiamente el dios, sino un sacerdote ataviado con los emblemas de Ehécatl Quetzalcóatl.

El ritual del autosacrificio fue muy practicado en Mesoamérica, y encontramos representaciones numerosas de este rito dentro del arte prehispánico. Sin embargo, para la región huasteca, hasta donde llegan mis conocimientos, no existen otras obras en que aparezca el autosacrificio. Esta temática parece estar circunscrita a la escuela local de Huilocintla.

En resumen, el relieve recién identificado como perteneciente a la cultura huasteca ayuda a fundamentar la creencia de que en Huilocintla existió un taller especializado en producir relieves de técnica depurada y con una temática particular. Es de esperarse que algún día se descubran otras piezas que confirmen esta suposición.

Bibliografia

CARREON, Ma Guadalupe

1976 Relieves Arte Huateco Prehispainios, trles de Mévio, Núm. 187, pp. 49-50, México, GARCIA PAYÓN, José.

1974 La Huasteca En Hisloria de .Mévico, Tomo 2, pp. 407-432, Salvat Editores, S A.

GUTIÉRREZ SOLANA, Nelly.

1976 La Pintura Mural de Tamuín, Arle Heatero Prehispánico, Artes de Mévico, Núm. 187, pp 55-57, México.

1976 El Arte del Tallado en Concha Arte Huasteco Prehispánico, Artes de México Núm. 187, pp 58-59, México.

Sculpture en Pierre

1963 Sculplure en Pierre de L'Ancien. Mexique, París.

SELER, Eduard

1904 Las Antiguas Colonias en la Región de la Huasteca. Colección de diserlaciones relaiivas a la filolagia y arquentogin americanas, Vol. 4, pp. 148-169. Traducción mecanuscrita.

1908 Monumentos de Huilocintla en el Cantón de Tuxpan, Veracruz. Colección de disertaciones retatirä́s a la fitutogźa y arqueologín americanas, Vol 8, pp 138-143. Traducción mecanuscrita.

TREJO, Silvia

1976 La Escultura. Arte Huaveco Prehispánico, Artes de México, Núm. 187, pp. 7-15, México

1978 Estilo Escultórico del Río Tamuín. Figuras masculinas. Tesis de Licenciado en Historia del Arte. Universidad Iberoamericana 